UDC 796.431.25.015.1

\title{
Skok - dominantni troskok
}

\author{
Kemal Idrizović \\ Fakultet za sport i fizičko vaspitanje, Nikšić \\ Nebojša Vujkov \\ Pokrajinski zavod za sport, Novi Sad \\ Ratko Pavlović \\ Fakultet sporta i fizičkog vaspitanja, Istočno Sarajevo
}

\begin{abstract}
Jumpings are biotic motor skills with dual-purpose. They serve to man to overcome space and obstacles. Two basic elements of jumping are bounce and landing. Besides the jumps, jumping character have movement structures, such as: hops and skips. Most often, each of them in their structure have the elements which modify the basic structure of jumping, however, meeting the basic principles of jumping so may be and defined. In athletics, there are four jumping disciplines: long jump, triple jump, high jump and pole vault. Triple Jump is very demanding athletic technical discipline. The entire movement structure, which represents triple jump, is divided into its constituent parts: running start, first jump (hop), second jump (step) and third jump (jump).
\end{abstract}

Keywords: athletics, jump, triple jump.
Sažetak: Skakanja su biotička motorička znanja dvostruke svrhe. Čovjeku služe da bi savladao prostor i savladao prepreke. Dva osnovna elementa skakanja su odraz, ili odskok i doskok. Osim skokova, karakter skakanja imaju i kretne strukture, kakvi su: poskoci, naskoci, saskoci i preskoci. Najčešće, pojedini od njih u svojoj strukturi posjeduju elemente koji modifikuju osnovnu strukturu skakanja, međutim, kako zadovoljavaju osnovne principe skakanja mogu se tako i definisati. $U$ atletici postoje četiri skakačke discipline, i to: skok udalj, troskok, skok uvis i skok motkom. Troskok je veoma zahtjevna atletska tehnička disciplina. Cjelokupna kretna struktura, koja predstavlja troskok, dijeli se na njegove sastavne djelove: zalet, prvi skok (poskok), drugi skok (korak) i treći skok (skok).

Ključne reči: atletika, skok, troskok.

Rad je primljen 13.08.2015.

Odobre 09.10.2015.

Kontakt podaci:

Vujkov Nebojša

Pokrajinski zavod za sport i medicinu sporta

Novi Sad, Masarikova 25/II

Tel: +38121572 224

E-mail:nesa.vujkov@gmail.com 


\section{Uvod}

Za razliku od hodanja i trčanja, skakanja nisu potpuno bezazlena kretanja, bez obzira na pojedine jednostavne oblike, već pripadaju visokorizičnom prirodnom obliku kretanja, posebno kada im se u domenu obuke ne pristupi na kvalitetan način. Skakanja su biotička motorička znanja dvostruke svrhe. Čovjeku služe da bi savladao prostor i savladao prepreke. Dva osnovna elementa skakanja su odraz, ili odskok i doskok. Ne postoji niti jedan oblik skakanja koji nije strukturiran od ta dva elementa. Na osnovu toga, u skakanja se ubrajaju sva ona kretanja, u kojima tijelo poslije opiranja o čvrstu podlogu, koristeći silu produkovanu vlastitim mišićima, prelazi u bespotporni položaj, tj. fazu leta, nakon koje slijedi doskok. Osim skokova, karakter skakanja imaju i kretne strukture, kakvi su: poskoci, naskoci, saskoci i preskoci. Najčešće, pojedini od njih u svojoj strukturi posjeduju elemente koji modifikuju osnovnu strukturu skakanja, međutim, kako zadovoljavaju osnovne principe skakanja mogu se tako i definisati.

U atletici postoje četiri skakačke discipline, i to: skok udalj, troskok, skok uvis i skok motkom. Prema osnovnoj definiciji skakanja, odnosno, skokova, od njih samo dvije u potpunosti ispunjavaju postavljene principe. To su skok udalj $\mathrm{i}$ skok uvis, dok su troskok i skok motkom modifikovani oblici skakanja u kojem se jedan skok ponavlja više puta, a kod skoka motkom koristi se i motka, kao vanjsko tijelo, odnosno, sprava. Atletski skokovi su veoma složena kretanja sačinjena od segmenta zaleta koji predstavlja ciklično kretanje i segmenta leta koji je aciklično kretanje. Kod svih atletskih skokova, podizanje tijela u fazu leta, postiže se pomoću zaleta i odraza i upravo od načina zaleta i njegovog jedinstva sa odrazom, let u svakoj od disciplina dobija svoj karakter. Bez obzira na to o kojem atletskom skoku je reč, željena daljina i visina skoka se postiže najvećom mogućom brzinom, koju skakač i skakačica mogu ostvariti. U tom smislu će u ovom radu biti analiziran troskok, kao atletska skakačka disciplina (Idrizović, 2010).

\section{Evolucija troskoka}

Prve informacije o troskoku su vezane za Antičku Grčku. U tim izvorima se pominju skokovi dužine od $16 \mathrm{~m}$. Pretpostavlja se da su takve dužine zbir tri pojedinačna skoka, a ne dužina jednog troskoka, kako on danas izgleda. $U$ istorijskim materijalima može se naći da je 1465. godine u Cirihu,
Švajcarska, nagrađen takmičar koji je pobijedio u troskoku. Danas se sa sigurnošću može tvrditi da je troskok potekao iz narodnih oblika troskoka. Njih je bilo i u našim krajevima, Irskoj, Njemačkoj, Škotskoj i Engleskoj. Današnji, zvanični troskok je nastao upravo iz engleskog i škotskog narodnog troskoka. Kod takvog troskoka prvi i drugi skok započinju odrazom sa iste noge, a treći sa druge. Upravo zbog toga, prvi skok koji ide takoreći sa iste na istu nogu, nosi ime poskok. Drugi, koji ide sa jedne na drugu nogu naziva se korak, a treći pošto jedini ima sve odlike skoka tako se i naziva. Pored ovog oblika troskoka korišćen je veoma dugo i troskok, kod kojeg su oba prva skoka bila sa iste na istu nogu. Tako se skakalo i na Prvim modernim olimpijskim igrama 1896 . godine, kada je pobijedio Amerikanac J. Connolly sa rezultatom 13,71m (Kyröläinen, Komi, Virmavirta i Isolehto, 2007).

Prema pravilima IAAF atletičaru su pri troskoku dozvoljena dva odraza jednom, a treći odraz drugom nogom (lijeva-lijeva-desna ili desnadesna-lijeva). Prvi svjetski rekord, zabilježen prema tim pravilima je iz 1911. godine, a rezultat od 15,52m ostvario je Amerikanac Daniel Ahearn. $\mathrm{U}$ istorijskom razvoju troskoka Ahaern je ostao zabilježen kao skakač koji je skratio korak drugog skoka na osnovu čega je dobio aktivno djelovanje odrazne noge, što će označiti pojavu udarne tehnike. Troskok je za muškarce na olimpijskom programu od samog početka Modernih olimpijskih igara, dakle 1896. godine u Atini. U olimpijskom programu za žene, troskok će se pojaviti tek 1996. godine na Olimpijskim igrama u Atlanti (Idrizović, 2010).

\section{Tehničke karakteristike}

Troskok je veoma zahtjevna atletska tehnička disciplina. Cjelokupna kretna struktura, koja predstavlja troskok, dijeli se na njegove sastavne djelove: zalet, prvi skok (poskok), drugi skok (korak) i treći skok (skok). Prvi skok se izvodi odrazom jedne i doskokom na istu nogu, drugi skok se izvodi odrazom sa te i doskokom na drugu nogu, a treći skok se izvodi odrazom sa noge na koju je izvršen doskok kod drugog skoka uz krajnji doskok na obje noge u jamu za doskok (slika 1). 


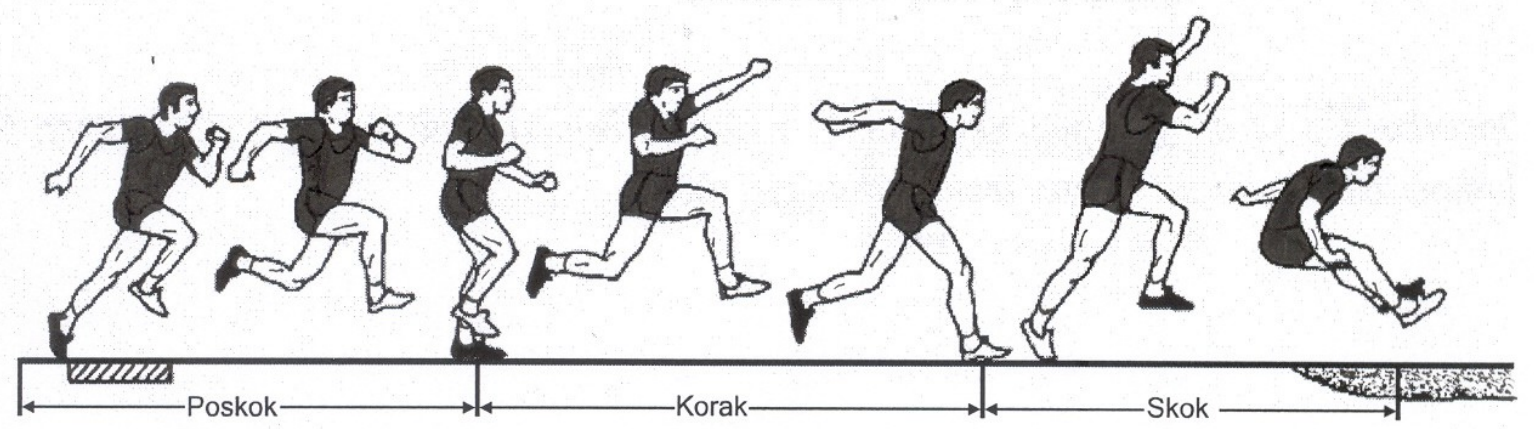

Slika 1: Troskok (poskok, korak i skok)

Tokom izvođenja troskoka veoma se jasno ispoljava sinergijsko djelovanje latentnog $i$ manifestnog motoričkog prostora svakog troskokaša. Kretna znanja (tehnički kvaliteti) i motoričke sposobnosti (brzinsko-snažne sposobnosti, specifični oblici izdržljivosti, gipkost), zajednički definišu krajnji rezultat troskoka, ali sa nešto većim udjelom motoričkih sposobnosti u krajnjem rezultatu. Zaključak je da koliko god tehnika troskokaša bila idealna, atletičar i atletičarka ne mogu računati na vrhunske rezultate u ovoj disciplini, ukoliko im navedene sposobnosti nisu na potrebnom nivou, a to je vrhunski.

Iako ih odlikuje veoma visok nivo podudarnosti, do danas su u razvoju troskoka figurirale tri tehnike: prirodna, trkačka i skakačka. Međutim, kako ranije tako i danas, mnogi skakači nisu skakali čistom tehnikom, ma o kojoj da je riječ. Veoma često su se pojavljivale modifikacije osnovnih tehnika, kao i njihove kombinacije. Modifikovanje pojedinih tehnika, a i kombinovanje pojedinih elemenata više različitih troskokaških tehnika, zasnovano je prije svega na pokušajima da se maksimalno iskoriste skakačevi potencijali i da se nedostacima ne dozvoli da dominiraju u realizaciji troskoka. Takvi pokušaji su nekada bili bez uspjeha, a povremeno su davali i vrhunske rezultate. Izvanredan primjer za to su čuveni američki skakači Willie Banks i Michael Conley i njihova modifikacija trkačke i skakačke tehnike, koja je u kretnom smislu započinjala trkačkom, u nastavku koristila kretanje ruku, kao u skakačkoj tehnici, ali je dužina skokova i brzina njihovog izvođenja bila bliža trkačkoj tehnici. Bitno je istaći da kretanje ruku nije jedini faktor koji definiše tehniku troskoka. U novije vrijeme kretanje ruku predstavlja samo jedan u nizu elemenata koji je uže određuju. Veoma sličan primjer je i tehnika najvećeg troskokaša svih vremena Jonathana Edwardsa, u kojoj se mogu uočiti elementi različitih tehnika, iako preovladava dvoručni oblik.

\section{Skok - dominantna tehnika}

Kako je ranije istaknuto troskok se pravilima IAAF izvodi na taj način što nakon zaleta skakač najprije doskače na nogu kojom se odrazio, zatim doskače na nogu sa koje će se odraziti u završni treći skok. U toku zaleta skakači postepeno podižu brzinu trčanja koja svoj maksimum dostiže u posljednjim koracima zaleta. Posljednji koraci zaleta su po karakteru slični posljednjim koracima zaleta kod skoka udalj, međutim, u odnosu na njih dešavaju se mnogo manje promjene u odnosu na trčanje tokom zaleta. Odrazna noga se u odnosu na skok udalj više savijena postavlja na odraznu dasku, a ugao uzlijetanja kod prvog skoka je 5 do $7^{\circ}$ manji od ugla uzlijetanja kod skoka udalj.

Bowerman i Freeman (1998) ističu biomehaničke principe troskoka.

- Horizontalna brzina je najvažniji faktor uticaja na dužinu skoka.

- Ugao odraza mora biti manji od onog kod skoka udalj.

- Aktivno blokiranje rukom ili rukama, u kombinaciji sa zamahom slobodne noge pod uglom od $90^{\circ}$ proizvodi veću silu reakcije i impuls.

- Svrha aktivnog (stopalo se u odnosu na skakača kreće unazad) doskoka je proizvesti veću brzinu kretanja odraznog stopala, nego što je to brzina tijela prema naprijed. Tako se održava horizontalna brzina.

- Za svaku akciju postoji jednaka i suprotna reakcija.

- Kada se skakač nalazi u vazduhu, više ništa ne može učiniti da skok bude duži.

- Prirodna rotacija prema naprijed može se odgoditi opružanjem ruku dolje i nazad, naglim kretnjama zamašne noge gore i naprijed ili ispružanjem obje noge prema dolje u položaju "C" s gornjim dijelom tijela.

- Ako je centar težišta ispred oslonca, doći će do pretjerane rotacije prema naprijed. 
- Produženje poluga usporava rotaciju, a skraćivanje je ubrzava.

Krejer (1982) navodi da tadašnji elitni troskokaši najbolje vrijeme na $100 \mathrm{~m}$ ostvaruju u intervalu između $10,4 \mathrm{i} 10,7 \mathrm{~s}$. Koriste 42 do $50 \mathrm{~m}$ dug zalet, koji prelaze sa 19 do 22 trčeća i 3 do 4 pripremna koraka. Tačna dužina zaleta zavisi od atletičarovih dostignuća, sposobnosti ubrzanja i koračne frekvencije.

Hay (1990) ističe da je istorijat istraživanja tehnike troskoka kratak i da se kroz to vrijeme koristio veći broj naziva kako bi se određene tehnike definisale. Tako su pojedini oblici nazivani po zemlji čiji su je atletičari usavršili (Japan, Australija, Rusija, Poljska), zatim prema visini koju su atletičari dostizali u pojedinim fazama skoka (ravna, skakačka, strma), i naravno trkačka i dvoručna simetrična tehnika, koje su dobile imena po mnoštvu konfuznih razloga.

Isti autor predlaže da je tehnike najbolje nazivati po tome koji je od tri skoka po svojoj dužini dominantan. Poskok-dominantna, skokdominantna i izbalansirana (proporcionalna).

Kod poskok-dominantne tehnike, dužina poskoka je najmanje za $2 \%$ duža od naredne najduže distance. Kao primjer navodi Poljaka Zdzisław Hoffmana i njegov pobjednički skok na I Svjetskom prvenstvu u Helsinkiju (17,42m), čiji je omjer skokova bio 38\%:33\%:29\%, i skok Hrista Markova $(17,92 \mathrm{~m})$ sa kojim je pobijedio na II Svjetskom prvenstvu u Rimu 1987. godine i čiji je omjer bio $36 \%, 30 \%: 34 \%$.

Kod skok-dominantne tehnike, dužina skoka je najmanje $2 \%$ duža od naredne najveće dužine. Primjer takve tehnike je svjetski rekord Willie
Banksa $(17,97 \mathrm{~m})$ iz 1985. godine, čije je omjer 35\%:28\%:37\% i koji je i danas sa ovim rezultatom četvrti skakač svih vremena.

Kod proporcionalne tehnike najduža distanca je manje od $2 \%$ veća od sljedeće najveće dužine. Primjer takvog skoka je pobjednički skok Al Joynera $(17,26 \mathrm{~m})$ na Olimpijskim igrama u Los Anđelesu 1984. godine, čiji je omjer 36\%:29\%:35\%.

Autor još podvlači da razni drugi autori ističu poskok-dominantnu tehniku i proporcionalnu kao optimalne, a da još uvijek niko, iako je tadašnji svjetski rekord i rekord prije njega bio postignut skok-dominantnom tehnikom, ne ističe kao vodeću tehniku u kojoj dominira dužina trećeg skoka.

Direktna potvrda ovih stavova Hay-a (1990) desiće se u skokovima Johnatana Edwardsa, sa kojima će skok-dominantna tehnika nastaviti svoju dominaciju koja traje i danas, 40 godina poslije svjetskog rekorda legendarnog Brazilca João Carlosa De Oliveire od 17,89m (1975), postignutog skok-dominatnom tehnikom. Na žalost De Oliveira, predstavnik rijetko spominjane brazliske škole će 1981. godine nakon saobraćajne nesreće izgubiti nogu i 1999. godine preminuti u 45. godini života od posljedica alkoholizma. Zissu (1984) će skok-dominantnu tehniku imenovati kao „técnica Oliveira“.

Hay (1993, modifikovano Moura, 2006) potvrđujući skok-dominantnu tehniku, kao optimalnu tehniku troskoka, iznosi podatke, odnosno, omjere dužina poskoka, koraka i skoka, svih svjetskih rekordera od 1911. godine do 1995. godine.

Tabela 1: Distribucija skokova troskoka, kod svjetskih rekorda (Hay 1993, modifikovano Moura, 2006)

\begin{tabular}{|l|c|c|c|c|c|c|}
\hline Atletičar & Godina & Zemlja & Rezultat (m) & Poskok (\%) & Korak (\%) & Skok (\%) \\
\hline Ahearne & 1911 & USA & 15,52 & 39,24 & 21,52 & 37,56 \\
\hline Winter & 1924 & AUS & 15,53 & 39,21 & 21,51 & 37,54 \\
\hline Oda & 1931 & JAP & 15,58 & 41,72 & 22,46 & 35,69 \\
\hline Nambu & 1932 & JAP & 15,72 & 40,71 & 28,12 & 31,36 \\
\hline Tajima & 1936 & JAP & 16,00 & 38,75 & 24,94 & 36,31 \\
\hline A. F. Da Silva & 1950 & BRA & 16,00 & 34,44 & 30,13 & 35,25 \\
\hline A. F. Da Silva & 1952 & BRA & 16,22 & 38,22 & 28,30 & 33,42 \\
\hline Sherbakov & 1953 & URSS & 16,23 & 37,03 & 30,56 & 32,29 \\
\hline A. F. Da Silva & 1955 & BRA & 16,56 & 37,86 & 30,07 & 32,07 \\
\hline Ryakhovskiy & 1958 & URSS & 16,59 & 38,94 & 29,90 & 31,04 \\
\hline Fyedoseyev & 1959 & URSS & 16,70 & 38,92 & 28,86 & 32,22 \\
\hline Schmidt & 1960 & POL & 17,03 & 35,23 & 29,42 & 35,29 \\
\hline Saneyev & 1968 & URSS & 17,39 & 36,23 & 29,04 & 34,73 \\
\hline Saneyev & 1972 & URSS & 17,44 & 37,27 & 28,27 & 34,46 \\
\hline J. C. de Oliveira & 1975 & BRA & 17,89 & $\mathbf{3 4 , 0 0}$ & $\mathbf{3 0 , 0 0}$ & $\mathbf{3 6 , 0 0}$ \\
\hline Banks & 1985 & USA & 17,97 & $\mathbf{3 5 , 1 7}$ & $\mathbf{2 7 , 6 0}$ & $\mathbf{3 7 , 2 3}$ \\
\hline Edwards & 1995 & GBR & 18,29 & $\mathbf{3 3 , 1 0}$ & $\mathbf{2 8 , 5 0}$ & $\mathbf{3 8 , 4 0}$ \\
\hline
\end{tabular}


Tehnički gledajući (tabela 1), preovladavajuća tehnika u XX vijeku je bila poskok-dominantna. To je i danas slučaj, a na to nas upućuju i vrijednosti adekvatnih parametara $\mathrm{u}$ narednim tabelama. Sa druge strane, svi najduži skokovi su do sada ostvareni skok-dominatnom tehnikom, što ne može biti slučajnost.

Kad je riječ o ženama, svjetski rekord Ukrajinke Inesse Kravets, 14,95m iz 1991. godine je ostvaren tehnikom koja je na prelazu između izbalansirane i poskok-dominantne. Omjer dužine njena tri skoka, u tada rekordnom troskoku je bio 36\%:30\%:34\%. Inessa Kravets će 1995. godine u Geteborgu postaviti i danas važeći svjetski rekord sa skokom od $15,50 \mathrm{~m}$.
Nakon tog skoka je izjavila da je proučavala tehniku Johnatana Edwardsa. Tokom razvoja ženskog troskoka još uvijek se nije pojavila vrhunska skakačica, čiji je omjer skokova ukazivao na skok-dominantnu tehniku. Najbolje skakačice u posljednjoj deceiji, Kamerunka Françoise Mbango Etone i Ruskinja Tatyana Lebedeva u svojim najboljim skokovima imaju treći skok kao najduži, ali je to još uvijek u okvirima proporcionalne tehnike.

Mendoza i sar. $(2008 ; 2009)$ su tokom Šestog svjetskog atletskog finala u Studgartu (tabele 2 i 3) i Svjetskog prvenstva u Berlinu (tabele 4 i 5), sproveli biomehaničku analizu takmičenja $\mathrm{u}$ troskoku, svih osam finalista i finalistikinja. Pojedini od tih parametara se mogu koristiti za definisanje tehnike kojom su skakali, kao i za određivanje njenih užih karakteristika.

Tabela 2: Biomehanička analiza troskoka muškarci (Mendoza i sar., 2008)

\begin{tabular}{|l|c|c|c|c|c|c|c|c|c|c|}
\hline Atletičar & Rezult. & D. po. & D.ko. & D.sko. & Hb.po. & Hb.ko. & Hb.po. & Vb.po. & Vb.ko. & Vb.po. \\
\hline Evora N. & $17,24 \mathrm{~m}$ & $6,39 \mathrm{~m}$ & 4,90 & 6,04 & $9,41 \mathrm{~m} / \mathrm{s}$ & 8,63 & 6,87 & $2,61 \mathrm{~m} / \mathrm{s}$ & 1,75 & 2,73 \\
\hline Gregorio J. & $17,09 \mathrm{~m}$ & $6,45 \mathrm{~m}$ & 5,06 & 5,81 & $9,48 \mathrm{~m} / \mathrm{s}$ & 8,39 & 6,36 & $2,58 \mathrm{~m} / \mathrm{s}$ & 1,98 & 3,03 \\
\hline Lewis R. & $17,01 \mathrm{~m}$ & $6,64 \mathrm{~m}$ & 5,05 & 5,49 & $9,25 \mathrm{~m} / \mathrm{s}$ & 7,97 & 6,54 & $2,68 \mathrm{~m} / \mathrm{s}$ & 2,07 & 2,50 \\
\hline Davis W. & $16,94 \mathrm{~m}$ & $6,08 \mathrm{~m}$ & 5,34 & 5,71 & $9,43 \mathrm{~m} / \mathrm{s}$ & 8,48 & 6,95 & $2,29 \mathrm{~m} / \mathrm{s}$ & 1,83 & 2,30 \\
\hline Valukevic D. & $16,94 \mathrm{~m}$ & $6,38 \mathrm{~m}$ & 4,83 & 5,83 & $9,03 \mathrm{~m} / \mathrm{s}$ & 8,06 & 6,38 & $2,66 \mathrm{~m} / \mathrm{s}$ & 1,92 & 3,04 \\
\hline Sands L. & $16,78 \mathrm{~m}$ & $6,44 \mathrm{~m}$ & 4,37 & 6,24 & $9,34 \mathrm{~m} / \mathrm{s}$ & 8,54 & 7,23 & $2,62 \mathrm{~m} / \mathrm{s}$ & 1,23 & 2,61 \\
\hline Friedek C. & $16,10 \mathrm{~m}$ & $5,68 \mathrm{~m}$ & 4,84 & 5,70 & $9,48 \mathrm{~m} / \mathrm{s}$ & 8,46 & 6,85 & $2,20 \mathrm{~m} / \mathrm{s}$ & 1,87 & 2,81 \\
\hline
\end{tabular}

Tabela 3: Biomehanička analiza troskoka žene (Mendoza i sar., 2008)

\begin{tabular}{|l|l|l|c|c|c|c|c|c|c|c|}
\hline Atletičarka & Rezult. & D. po. & D.ko. & D.sko. & Hb.po. & Hb.ko. & Hb.po. & Vb.po. & Vb.ko. & Vb.po. \\
\hline Pyatykh A. & $14,78 \mathrm{~m}$ & $5,62 \mathrm{~m}$ & 3,94 & 5,24 & $8,11 \mathrm{~m} / \mathrm{s}$ & 7,56 & 6,72 & $2,60 \mathrm{~m} / \mathrm{s}$ & 1,37 & 2,34 \\
\hline Lebedeva T. & $14,63 \mathrm{~m}$ & $5,42 \mathrm{~m}$ & 3,82 & 5,58 & $8,56 \mathrm{~m} / \mathrm{s}$ & 8,00 & 6,67 & $2,28 \mathrm{~m} / \mathrm{s}$ & 1,00 & 2,64 \\
\hline Sestak M. & $14,63 \mathrm{~m}$ & $5,27 \mathrm{~m}$ & 4,09 & 5,30 & $8,28 \mathrm{~m} / \mathrm{s}$ & 7,68 & 6,52 & $2,36 \mathrm{~m} / \mathrm{s}$ & 1,52 & 2,63 \\
\hline MbangoE F. & $14,50 \mathrm{~m}$ & $5,11 \mathrm{~m}$ & 4,47 & 5,09 & $8,48 \mathrm{~m} / \mathrm{s}$ & 7,77 & 6,50 & $2,08 \mathrm{~m} / \mathrm{s}$ & 1,88 & 2,38 \\
\hline Udmurtova O. & $14,46 \mathrm{~m}$ & $5,26 \mathrm{~m}$ & 4,33 & 5,04 & $8,39 \mathrm{~m} / \mathrm{s}$ & 7,54 & 6,18 & $2,28 \mathrm{~m} / \mathrm{s}$ & 2,00 & 2,48 \\
\hline Saladuha O. & $14,40 \mathrm{~m}$ & $5,40 \mathrm{~m}$ & 3,97 & 5,06 & $8,14 \mathrm{~m} / \mathrm{s}$ & 7,44 & 6,50 & $2,59 \mathrm{~m} / \mathrm{s}$ & 1,45 & 2,51 \\
\hline Veldakova D. & $13,89 \mathrm{~m}$ & $5,17 \mathrm{~m}$ & 3,64 & 5,19 & $8,41 \mathrm{~m} / \mathrm{s}$ & 7,97 & 6,80 & $2,29 \mathrm{~m} / \mathrm{s}$ & 1,38 & 2,26 \\
\hline De Oliveira G. & $13,55 \mathrm{~m}$ & $5,02 \mathrm{~m}$ & 4,00 & 4,61 & $8,28 \mathrm{~m} / \mathrm{s}$ & 7,52 & 6,70 & $2,12 \mathrm{~m} / \mathrm{s}$ & 1,61 & 1,86 \\
\hline
\end{tabular}

Tabela 4: Biomehanička analiza troskoka muškarci (Mendoza i sar., 2009)

\begin{tabular}{|l|c|l|c|c|c|c|c|c|c|c|}
\hline Atletičar & Rezult. & D. po. & D. ko. & D. sko. & Hb.po. & Hb.ko. & Hb.po. & Vb.po. & Vb.ko. & Vb.po. \\
\hline Idowu P. & $17,73 \mathrm{~m}$ & $6,49 \mathrm{~m}$ & 5,41 & 6,02 & $9,72 \mathrm{~m} / \mathrm{s}$ & 8,48 & 7,01 & $2,45 \mathrm{~m} / \mathrm{s}$ & 1,94 & 2,70 \\
\hline Evora N. & $17,55 \mathrm{~m}$ & $6,51 \mathrm{~m}$ & 5,41 & 5,68 & $9,19 \mathrm{~m} / \mathrm{s}$ & 8,25 & 6,50 & $2,68 \mathrm{~m} / \mathrm{s}$ & 1,94 & 3,14 \\
\hline Copello A. & $17,36 \mathrm{~m}$ & $6,01 \mathrm{~m}$ & 5,77 & 5,92 & $9,49 \mathrm{~m} / \mathrm{s}$ & 8,27 & 6,93 & $2,27 \mathrm{~m} / \mathrm{s}$ & 2,21 & 2,53 \\
\hline Sands L. & $17,32 \mathrm{~m}$ & $6,52 \mathrm{~m}$ & 5,20 & 5,62 & $9,5 \mathrm{~m} / \mathrm{s}$ & 8,52 & 7,26 & $2,48 \mathrm{~m} / \mathrm{s}$ & 2,10 & 2,36 \\
\hline Girat A. & $17,26 \mathrm{~m}$ & $6,16 \mathrm{~m}$ & 5,41 & 5,88 & $9,14 \mathrm{~m} / \mathrm{s}$ & 8,15 & 7,06 & $2,47 \mathrm{~m} / \mathrm{s}$ & 2,32 & 2,45 \\
\hline Li Y. & $17,23 \mathrm{~m}$ & $6,33 \mathrm{~m}$ & 5,24 & 5,75 & $9,18 \mathrm{~m} / \mathrm{s}$ & 8,15 & 6,94 & $2,64 \mathrm{~m} / \mathrm{s}$ & 2,26 & 2,57 \\
\hline Spasovkhodskiy I & $16,91 \mathrm{~m}$ & $6,47 \mathrm{~m}$ & 4,80 & 5,69 & $9,35 \mathrm{~m} / \mathrm{s}$ & 8,24 & 7,11 & $2,39 \mathrm{~m} / \mathrm{s}$ & 1,97 & 2,67 \\
\hline Gregorio J. & $16,89 \mathrm{~m}$ & $6,33 \mathrm{~m}$ & 5,10 & 5,72 & $9,42 \mathrm{~m} / \mathrm{s}$ & 8,28 & 7,11 & $2,48 \mathrm{~m} / \mathrm{s}$ & 1,75 & 2,62 \\
\hline
\end{tabular}


Tabela 5: Biomehanička analiza troskoka žene (Mendoza i sar., 2009)

\begin{tabular}{|l|l|l|c|c|c|c|c|c|c|c|}
\hline Atletičarka & Rezult. & D. po. & D. ko. & D. sko. & Hb.po. & Hb.ko. & Hb.po. & Vb.po. & Vb.ko. & Vb.po. \\
\hline Savigne Y. & $14,95 \mathrm{~m}$ & $5,50 \mathrm{~m}$ & 4,04 & 5.49 & $8.63 \mathrm{~m} / \mathrm{s}$ & 8.22 & 6.87 & $2.49 \mathrm{~m} / \mathrm{s}$ & 1.24 & 2.67 \\
\hline Gay M. & $14,61 \mathrm{~m}$ & $5,35 \mathrm{~m}$ & 4,43 & 5.00 & $8.12 \mathrm{~m} / \mathrm{s}$ & 7.30 & 6.07 & $2.34 \mathrm{~m} / \mathrm{s}$ & 1.70 & 2.57 \\
\hline Pyatykh A. & $14,53 \mathrm{~m}$ & $5,46 \mathrm{~m}$ & 4,31 & 4.95 & $8.21 \mathrm{~m} / \mathrm{s}$ & 7.46 & 6.32 & $2.46 \mathrm{~m} / \mathrm{s}$ & 1.93 & 2.48 \\
\hline Topic B. & $14,52 \mathrm{~m}$ & $5,30 \mathrm{~m}$ & 4,13 & 5.20 & $8.45 \mathrm{~m} / \mathrm{s}$ & 7.80 & 6.89 & $2.30 \mathrm{~m} / \mathrm{s}$ & 1.72 & 2.14 \\
\hline Smith T. & $14,48 \mathrm{~m}$ & $5,57 \mathrm{~m}$ & 4,38 & 4.53 & $8.34 \mathrm{~m} / \mathrm{s}$ & 7.38 & 6.00 & $2.39 \mathrm{~m} / \mathrm{s}$ & 1.84 & 1.78 \\
\hline Lebedeva T. & $14,48 \mathrm{~m}$ & $5,33 \mathrm{~m}$ & 4,30 & 5.00 & $8.59 \mathrm{~m} / \mathrm{s}$ & 7.80 & 6.30 & $2.24 \mathrm{~m} / \mathrm{s}$ & 1.84 & 2.32 \\
\hline Bujin C. & $14,26 \mathrm{~m}$ & $5,25 \mathrm{~m}$ & 4,05 & 5.11 & $8.00 \mathrm{~m} / \mathrm{s}$ & 7.37 & 6.11 & $2.49 \mathrm{~m} / \mathrm{s}$ & 1.57 & 2.80 \\
\hline Veldakova D. & $14,25 \mathrm{~m}$ & $5,24 \mathrm{~m}$ & 3,96 & 5.06 & $8.48 \mathrm{~m} / \mathrm{s}$ & 7.90 & 6.70 & $2.24 \mathrm{~m} / \mathrm{s}$ & 1.19 & 2.24 \\
\hline
\end{tabular}

Na slici 1 je Tatyana Lebedeva i njen skok od $14,63 \mathrm{~m}$. Posljednja dva koraka $(2,11$ i $2,16 \mathrm{~m})$ prije odraza je trčala prosječnom brzinom $9,085 \mathrm{~m} / \mathrm{s}$, vrijeme kontakta sa podlogom tokom odraza za poskok je bilo $0,11 \mathrm{~s}$, tokom odraza za korak $0,15 \mathrm{~s}$, a tokom odraza za skok $0,16 \mathrm{~s}$. Na slici 4 je Nelson Évora sa skokom 17,24m. Posljednja dva koraka (2,33 i $2,15 \mathrm{~m})$ prije odraza je trčao prosječnom brzinom $10,305 \mathrm{~m} / \mathrm{s}$, vrijeme kontakta sa podlogom tokom odraza za poskok je bilo $0,11 \mathrm{~s}$, tokom odraza za korak $0,13 \mathrm{~s}$, a tokom odraza za skok $0,18 \mathrm{~s}$.

Na slici 2 je Li Yanxi sa skokom 17,23m. Posljednja dva koraka $(2,30$ i $2,46 \mathrm{~m})$ prije odraza je trčao prosječnom brzinom $9,94 \mathrm{~m} / \mathrm{s}$, vrijeme kontakta sa podlogom tokom odraza za poskok je bilo $0,11 \mathrm{~s}$, tokom odraza za korak $0,14 \mathrm{~s}$, a tokom odraza za skok 0,14s. Rastojanje od 11-og do 6-og metra prije odrazne daske je trčao prosječnom brzinom $9,74 \mathrm{~m} / \mathrm{s}$, a rastojanje od $6-\mathrm{og}$ do jednog metra prije odraza brzinom od $10,02 \mathrm{~m} / \mathrm{s}$.

$\mathrm{Na}$ slici 3 je Igor Spasovkhodskiy sa skokom $16,91 \mathrm{~m}$. Posljednja dva koraka $(2,55$ i $2,49 \mathrm{~m})$ prije odraza je trčao prosječnom brzinom $10,075 \mathrm{~m} / \mathrm{s}$, vrijeme kontakta sa podlogom tokom odraza za poskok je bilo $0,12 \mathrm{~s}$, tokom odraza za korak $0,17 \mathrm{~s}$, a tokom odraza za skok 0,18s. Rastojanje od 11-og do 6-og metra prije odrazne daske je trčao prosječnom brzinom $10,08 \mathrm{~m} / \mathrm{s}$, a rastojanje od 6-og do jednog metra prije odraza brzinom od $10,09 \mathrm{~m} / \mathrm{s}$.

$\mathrm{Na}$ slici 5 je Phillips Idowu sa skokom 17,73m. Posljednja dva koraka (2,58 i 2,49m) prije odraza je trčao prosječnom brzinom $10,50 \mathrm{~m} / \mathrm{s}$, vrijeme kontakta sa podlogom tokom odraza za poskok je bilo $0,13 \mathrm{~s}$, tokom odraza za korak $0,16 \mathrm{~s}$, a tokom odraza za skok $0,17 \mathrm{~s}$. Rastojanje od 11-og do 6-og metra prije odrazne daske je trčao prosječnom brzinom $10,41 \mathrm{~m} / \mathrm{s}$, a rastojanje od $6-\mathrm{og}$ do jednog metra prije odraza brzinom od $10,49 \mathrm{~m} / \mathrm{s}$.

Kako je skok Phillipsa Idowua po kvalitetu najbliži najboljim ostvarenjima Johnatana Edwardsa (18,16 i 18,29m), poređenje pojedinih parametara ovih skokova, kao i skoka Briana Wellmana (17,62m), takođe sa Svjetskog prvenstva u Geteborgu 1995. godine, daje dodatne informacije o vrhunskoj tehnici troskoka, kao i o specifičnosti svakog troskoka pojedinačno (tabela 6).
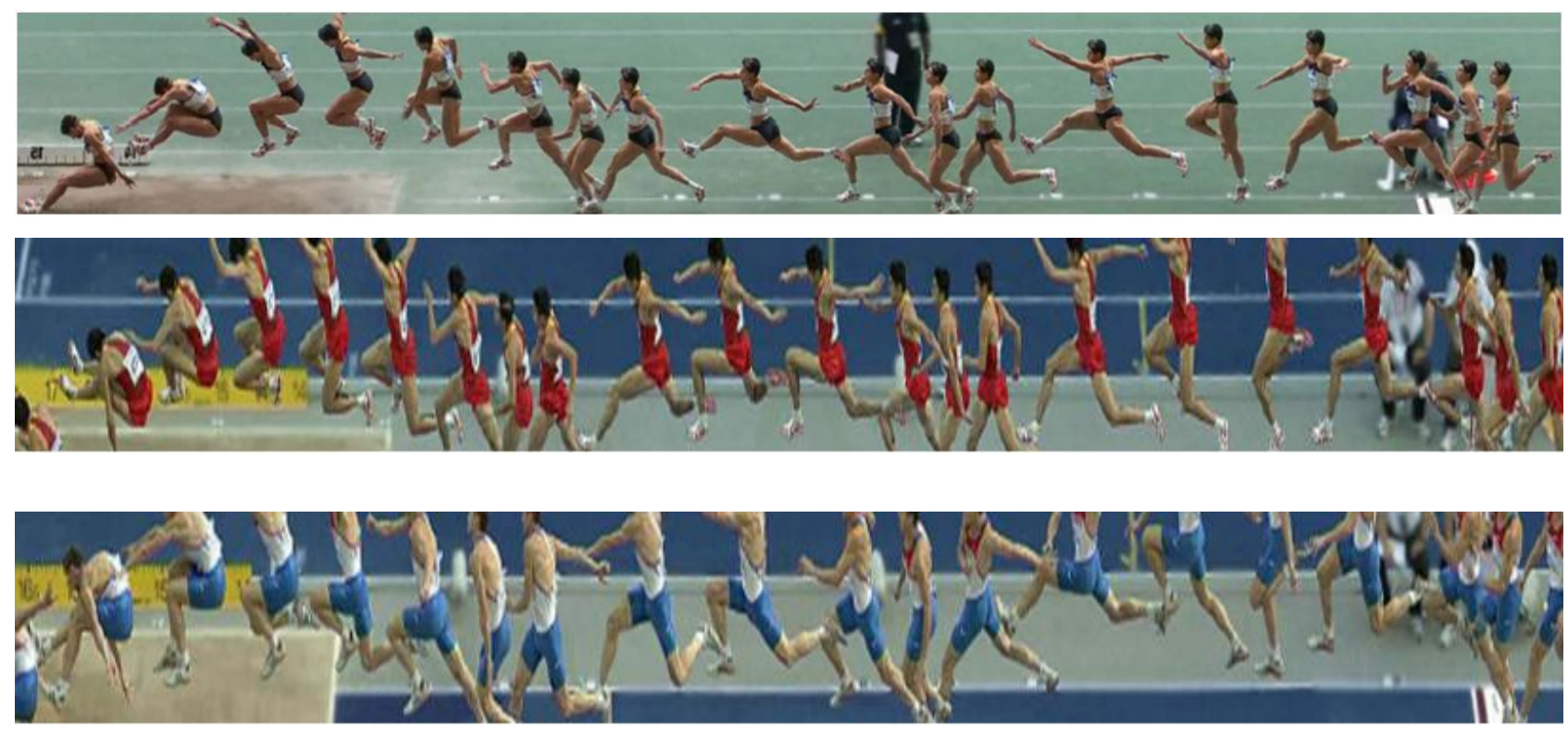

Slike 2,3, i 4 trkača (Mendoza i sar., 2008; 2009) 

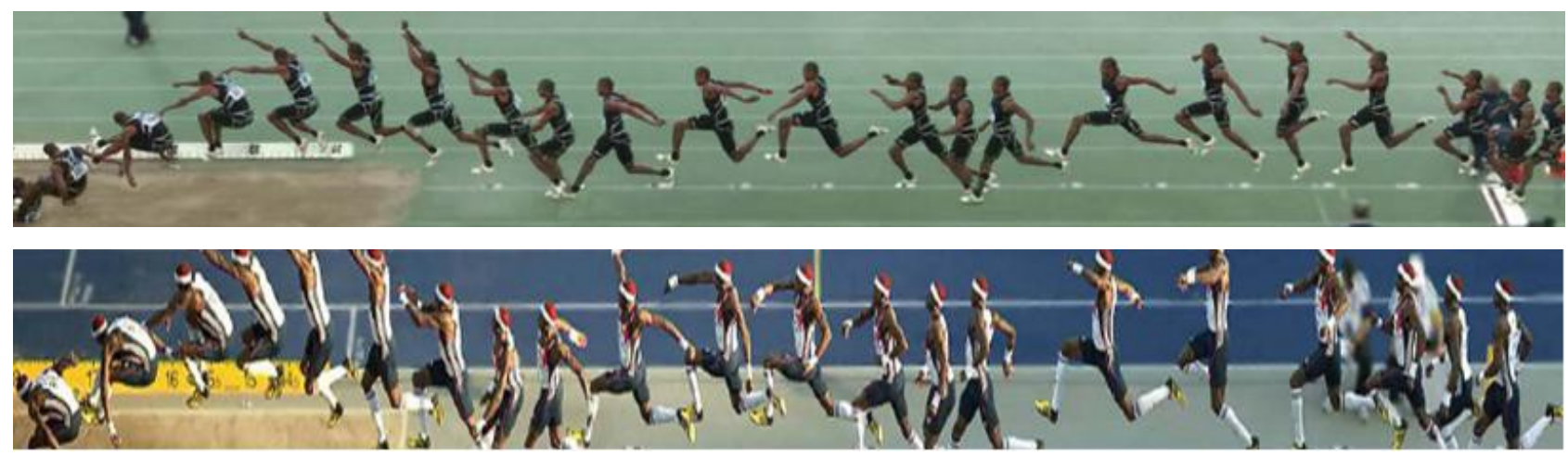

Slika 5 Dvoručna i 6 Kombinovana tehnika (Mendoza i sar., 2008; 2009)

Tabela 6: Kinematički parametri skokova Johnatana Edwardsa, Briana Wellmana i Phillipsa Idowua ( modifikovano prema Aagaard i sar., 1995; Mendoza i sar. 2009)

\begin{tabular}{|l|c|c|c|c|c|c|c|}
\hline Atletičar & Rezultat & Br. poskok & Br. korak & Br. skok & Ug.odr.poskok & Ug.odr.korak & Ug.odr.skok \\
\hline Edwards J. & $18,29 \mathrm{~m}$ & $9,48 \mathrm{~m} / \mathrm{s}$ & $8,39 \mathrm{~m} / \mathrm{s}$ & $7,20 \mathrm{~m} / \mathrm{s}$ & $16^{\circ}$ & $14,5^{\circ}$ & $19^{\circ}$ \\
\hline Edwards J. & $18,16 \mathrm{~m}$ & $9,57 \mathrm{~m} / \mathrm{s}$ & $8,53 \mathrm{~m} / \mathrm{s}$ & $7,26 \mathrm{~m} / \mathrm{s}$ & $15^{\circ}$ & $15^{\circ}$ & $19^{\circ}$ \\
\hline Wellman B. & $17,62 \mathrm{~m}$ & $9,17 \mathrm{~m} / \mathrm{s}$ & $8,12 \mathrm{~m} / \mathrm{s}$ & $6,44 \mathrm{~m} / \mathrm{s}$ & $14^{\circ}$ & $17^{\circ}$ & $22^{\circ}$ \\
\hline Idowu P. & $17,73 \mathrm{~m}$ & $9,72 \mathrm{~m} / \mathrm{s}$ & $8,48 \mathrm{~m} / \mathrm{s}$ & $7,01 \mathrm{~m} / \mathrm{s}$ & $14^{\circ}$ & $13^{\circ}$ & $21^{\circ}$ \\
\hline
\end{tabular}

Tabela 7: Kinematički parametri skokova Johnatana Edwardsa i Phillipsa Idowua (modifikovano prema Portnoy, 1997; Mendoza i sar. 2009)

\begin{tabular}{|l|c|c|c|}
\hline Atletičar & Rezultat & Brzina 11 - 6m & Brzina 6 - 1m \\
\hline Edwards J. & $18,29 \mathrm{~m}$ & $9,80 \mathrm{~m} / \mathrm{s}$ & $11,90 \mathrm{~m} / \mathrm{s}$ \\
\hline Idowu P. & $17,73 \mathrm{~m}$ & $10,41 \mathrm{~m} / \mathrm{s}$ & $10,49 \mathrm{~m} / \mathrm{s}$ \\
\hline
\end{tabular}

Analizirajući vrijednosti parametara iz prethodnih tabela, može se zaključiti da brzina trčanja zaleta u troskoku, kao i brzina kretanja skakača tokom pojedinih faza troskoka nije standardan i dominantan faktor krajnjeg rezultata. Međutim, evidentno je da proporcionalno povećanje brzine svih elemenata troskoka, u zavisnosti i od drugih faktora (fizičkih i tehničkih), može veoma pozitivno uticati na njegovo poboljšanje.
Hutt (1988) naglašava da korelacija između finalne brzine (od 6. do 1. metra prije odraza) i postignutog rezultata $\mathrm{u}$ troskoku nije statistički značajna, kao što je kod skoka udalj. Eksplozivna snaga skakačkog tipa i tehnički potencijali imaju značajno veći uticaj na krajnji rezultat kod troskoka, nego kod skoka udalj. Međutim, na osnovu srednjih vrijednosti narednih parametara, stotina biomehanički analiziranih troskoka, autor predstavlja vrijednosti (tabela 8), koje se veoma kvalitetno mogu koristiti.

Tabela 8: Brzina zaleta i očekivani rezultat u troskoku (Hutt, 1988)

\begin{tabular}{|c|c|}
\hline $\begin{array}{c}\text { Brzina zaleta na distnci 6-1m prije odrazne daske } \\
(\mathbf{m} / \mathbf{s})\end{array}$ & Rezultat u troskoku (m / $\mathbf{\pm 0 , 5 0 m )}$ \\
\hline 10,50 & 17,50 \\
\hline 10,25 & 17,00 \\
\hline 10,00 & 16,50 \\
\hline 9,80 & 16,00 \\
\hline 9,60 & 15,50 \\
\hline 9,45 & 15,00 \\
\hline 9,40 & 14,50 \\
\hline
\end{tabular}


Moura i sar. (2003), takođe, ističu da brzina trčanja zaleta troskoka, kod atletičara ima pozitivnu, ali i ne izrazito visoku povezanost sa rezultatom. Izračunati koeficijent korelacije je iznosio $\mathrm{r}=0$,58. Isto tako, autori navode, da je povezanost brzine trčanja zaleta i rezultata u skoku udalj značajno veća i kod atletičara $(r=0,72)$ i kod atletičarki $(\mathrm{r}=0,74)$.
Na sličan način kao u tabelama 6. i 7. moguće je uporediti rezultate i ženskog troskoka. U tabeli 9. su date brzine trčanja dva osnovna segmenta zaleta troskoka i dužine poskoka, koraka i skoka, svjetskog rekorda Innese Kravets iz 1991. godine, $14,95 \mathrm{~m}$ i identičnog rezultata Yargelis Savigne, sa kojim je postala svjetska šampionka 2009. godine u Berlinu.

Tabela 9: Kinematički parametri skokova Inesse Kravets i Yargelis Savigne (modifikovano prema Kreyer, 1992; Mendoza i sar. 2009)

\begin{tabular}{|l|c|c|c|c|c|c|}
\hline Atletičar & Rezultat & Brzina 11 - 6m & Brzina 6 - 1m & Poskok & Korak & Skok \\
\hline Kravets I. & $14,95 \mathrm{~m}$ & $8,94 \mathrm{~m} / \mathrm{s}$ & $9,14 \mathrm{~m} / \mathrm{s}$ & $5,35 \mathrm{~m}$ & $4,30 \mathrm{~m}$ & $5,30 \mathrm{~m}$ \\
\hline Savigne Y. & $14,95 \mathrm{~m}$ & $\approx 9,20 \mathrm{~m} / \mathrm{s}$ & $9,36 \mathrm{~m} / \mathrm{s}$ & $5,42 \mathrm{~m}$ & $4,04 \mathrm{~m}$ & 5,49 \\
\hline
\end{tabular}

Može se uočiti da obje skakačice skaču izbalansiranom (proporcionalnom) tehnikom (koja je sa poskok-dominantnom tehnikom, najčešća kod atletičarki), ali ne istim oblikom te tehnike. Omjer tri skoka kod Kravets je 36\%:28,7\%:35,3, dok je kod Savigne 36,28\%:27,02\%:36,70\%. Učešće koraka u ukupnom skoku kod Kravets je znatno veći, pa samim tim i zbir poskoka i skoka koji je $71,3 \%$ odgovara raspodjeli ove dvije dužine u odnosu kao kod muškaraca koji skaču ovom tehnikom (kod muškaraca je od 68 do $72 \%$ ). Kod Savigne je taj skor $\approx 73 \%$. U još jednom parametru je Kravets na nivou atletičara koji skaču $17 \mathrm{~m}$. Radi se o dužini kontakta tokom sva tri odraza. Za atletičare koji skaču oko $17 \mathrm{~m}$, vrijeme trajanja kontakta sa podlogom je redom po skokovima 0,13 , 0,15 i 0,165 s. Kravets je „ostajala“ na tlu 0,125, 0,166 i 0,166s, dok je Savigne dodirivala podlogu u trajanju od $0,11,0,11$ i $0,15 \mathrm{~s}$. Zaključak koji se na osnovu navedenih parametara može izvesti je da iako ova dva skoka imaju identičnu dužinu, ipak se radi o potpuno dvije različite tehničke varijante. Sve to ide u prilog činjenici da se pojedinac ne prilagođava tehnici, već se tehnika mora prilagođavati njegovim fizičkim i tehničkim potencijalima, što sa druge strane znači da će atletičar ili atletičarka (u vrhunskim uslovima) „odrediti-izabrati“" tehniku, a ne tehnika njih.
U troskoku ne postoji jedna tehnika koja bi se mogla preporučiti svakom skakaču, prateći i uzimajući $u$ obzir njegove individualne karakteristike. Finalno rješenje u poskokdominantnoj, skok-dominantnoj ili izbalansiranoj tehnici, mora biti rezultat fizičkih i tehničkih kvaliteta atletičara i atletičarke.

\section{Zaključak}

Ne smijemo zaboraviti da tehničke varijante moraju biti usavršene na naučnim principima, a da onda, ponekad, vrhunski svjetski atletičari kopiraju jedan drugog ili jednostavno prate svoja osjećanja, što onda uništi naše stavove. U svakom slučaju, gledam naprijed da saznam više o skakačkom omjeru Johnatana Edwardsa, što nam može dati više informacija na ovu temu (Moura, 1996). 


\section{Literatura}

1. Bowerman, J.W., Freeman, H.W. (1991). High-performance training for track and field. Champaign, IL.

2. Hay, J.G. \& Reid, J.G. (1988). Anotomy, Mechanics, and Human Motion (2nd Ed). Englewood Cliffs: Prentice-Hall, inc.

3. Hay, J.G. (1990) The biomechanics of triple jump techniques. In: BRÜGGEMANN, G.P. \& RUHL, J.K. (eds), Techniques in Athletics Congress Proceedings. Köln: Deutsche Sporthochschule Köln.

4. Hay, J.G. (1992). The biomechanics of the triple jump: a review. Journal of Sports Sciences, $10,343-78$.

5. Hay, J. G. (1993). The biomechanics of sports techniques (4 ed.): Prentice Hall.

6. Hutt E. (1988). Model technique analysis sheet for the horizontal jumps: Part II. The triple jump. New Studies in Athletics, 4 (3), 63-66.

7. Idrizović, K. (2010). Atletika I i II. Univerzitet Crne Gore, Podgorica.

8. Kreyer, V. (1988). The run-up and the take-off in the triple jump. In: JARVER J. (ed), The jumps: contemporary theory, technique and training (3rd edition). Los Angeles, CA: Tafnews Press.

9. Kreyer, V. (1993). About the female triple jump. Modern Athlete and Coach, 31, 13-17.

10. Kyröläinen, H.; Komi, P.V.; Virmavirta, M. \& Isolehto, J. (2007). Biomechanical Analysis of the Triple Jump. Jyvaskyla: University of Jyvaskyla.

11. Mendoza, L.; Nixdorf, E. \& Isele, R. (2006) Gesetzmäßigkeiten des horizontalsprungs. Leichtathletik, 17, 26-29.

12. Mendoza, L. \& Nixdorf, E. (2010). Scientific Research Project Biomechanical Analysis at the Berlin 2009 (http:/ www.osp-hessen.de).

13. Moura, N.A., Duarte, M., Mochizuki, L., Sá, M.R. e Amadio, A.C. (1994). Distribuição dos Saltos Parciais na Prova do Salto Triplo Masculino e Feminino - Análise Biomecânica. Boletin IAAF - Centro Regional de Desarollo - Santa Fé. 12.

14. Moura, N.A. (1996). Is the Jump-dominated technique in the triple jump the best for all? (letter to the editor). Track Coach, 136:4352-4353.

15. Moura, N.A., Moura, T.F.P., and Borin, J.P. (2005). Approach speed and performance in the horizontal jumps: What do Brazilian athletes do? New Studies in Athletics, 20(3):43-48.

16. Portnoy G. (1997). Differences in some triple jump rhythm parameters. Modern Athlete and Coach, 35,11-14.

17. Zissu, M. (1980). Mechanical characteristics of the triple jump. Unpublished master's thesis, University of Southern California, Los Angeles.

18. Zissu, M. (1984). Características mecánicas de la fase de pique-despegue en el salto triple. Rev. Stadium, 103:16-21. 